\title{
A educação frente à diferença/diversidade sexual
}

\author{
Rogério Diniz Junqueira \\ Instituto Nacional de Estudos e Pesquisas Educacionais Anísio Teixeira/Inep, Brasília-DF, Brasil.
}

rogeriodinizjunqueira@gmail.com

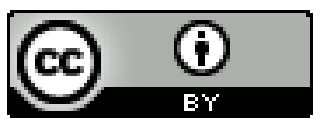

Educação: teoria e prática, Rio Claro, SP, Brasil - elSSN: 1981-8106

Está licenciada sob Licença Creative Common

\section{Resumo}

O artigo defende a desestabilização de lógicas, pressupostos, normas, valores e práticas que fazem da escola um espaço normalizador que fabrica e hierarquiza corpos, sujeitos e identidades a partir de disposições heteronormativas. Heterossexismo e homofobia não são apenas problemas que a escola meramente herdaria da sociedade, mas elementos centrais do cotidiano e do currículo: a escola os consente, cultiva e ensina. São limitados os enfrentamentos à homofobia pautados em pressupostos essencialistas e/ou que não questionam a normatividade que a gera e alimenta. $O$ artigo reitera a importância pedagógica da diferença/diversidade e do encontro com o outro e defende a promoção do reconhecimento da diferença/diversidade sexual a partir de pedagogias mais abertas, pautadas pela ética democrática e dos direitos humanos.

Palavras-chave: Educação. Heterossexismo. Homofobia. Diferença. Diversidade.

\section{The education facing the sexual difference/diversity}

\begin{abstract}
The article advocates the destabilization of logic, assumptions, norms, values and practices that make it a normalizing space where and bodies, subjects and identities are built in accordance with heteronormative. Heterosexism and homophobia are not just problems that the school inherits from society, but the core elements of everyday life and the school curriculum: the school allows, cultivates and teaches heterosexism and homophobia. Struggles against homophobia based on essentialist assumptions or that do not question the heteronormative assumptions that generate and feed it are fairly limited. Difference, diversity and the encounter with the "other" have a great pedagogical importance. It
\end{abstract}


demands the acknowledgment of sexual difference and diversity based on more open pedagogies, guided by democratic ethics and human rights.

Keywords: Body. Physical Education. Conceptions. Health.

Conhecer o Outro é conhecer melhor a si mesmo.

(MATOS, 2006, p. 65)

O campo da educação se constituiu, historicamente, como um espaço disciplinador, normalizador e reprodutor de desigualdades; e tomar consciência disso constitui passo decisivo para se desestabilizar lógicas e compromissos de modelos educacionais concebidos para estar a serviço de poucos. No sentido aqui empregado,

Normalizar significa eleger - arbitrariamente - uma identidade específica como parâmetro em relação ao qual as outras identidades são avaliadas e hierarquizadas. Normalizar significa atribuir a essa identidade todas as características positivas possíveis, em relação às quais as outras só podem ser avaliadas de forma negativa (SILVA, 2000, p.83).

Trata-se de processos que, assim, implicam hierarquizações e marginalizações, tornando necessária a problematização radical de suas dinâmicas, de suas relações de poder, bem como da produção e do acionamento de seus dispositivos. No entanto, a sutileza em que se dão é um dos fatores que lhes conferem grande força: a naturalização e a imposição da norma são invisibilizadas. Desse modo, ações voltadas a problematizá-las são confundidas ou rechaçadas como propaganda. Uma curiosa inversão, pois todos/as somos submetidos/as a processos de construção de corpos, sujeitos e identidades que, no caso da sexualidade, devem estar sintonizados com a heterossexualização compulsória.

O êxito de ações no âmbito de políticas educacionais voltadas a promover a cultura dos direitos humanos e o reconhecimento da diferença ${ }^{1}$ e da diversidade sexual ${ }^{2}$ está sempre

\footnotetext{
${ }^{1}$ Bhabha (2001) fala em diferença em vez de diversidade por conta da tendência de se pensar esta última como uma realidade ou condição já dada, estática, uma reafirmação do supostamente idêntico. Por isso, ele, ao promover a inversão da concepção estruturalista de diferença (ali, uma matriz de criação de identidade), preconiza o atravessamento das fronteiras, de modo a fazer da experiência da alteridade algo a ser vivido como assunção consciente de uma identidade híbrida, cindida e subversiva.

${ }^{2}$ A noção de diversidade sexual é aqui empregada em referência a um conjunto dinâmico, plural e multíplice de práticas, formas e experiências relacionadas a vivências, prazeres e desejos sexuais, vinculados a processos de (re)configurações, representações, manifestações e assunções identitárias, geralmente objetivadas em termos de identidades, preferências, orientações e expressões sexuais e de gênero.
} 
relacionado às condições objetivas dos campos sociais onde elas têm lugar e a partir dos quais se desdobram. ${ }^{3}$ Tais políticas tanto dependem dessas condições quanto podem sobre elas incidir, modificando-as, entre inúmeros conflitos e concorrências. Também por isso, em torno de cada um de seus elementos, gravitam disputas sociais, simbólicas, políticas, econômicas, institucionais que também agem constitutivamente em relação ao campo escolar, à sua cultura, às suas rotinas e ambiências, às suas relações de poder ${ }^{4}$, e repercutem nas suas articulações com outros espaços sociais, ao mesmo tempo em que se ressentem de tensões e disputas originadas alhures. Não surpreende que, aí, as tensões possam ser incessantes e envolver diversos setores em calorosas disputas em torno de várias concepções de escola, currículo, docência, livro didático, inclusão, sociedade, Estado, público/privado, laicidade, família, direitos humanos etc. Tensões que se atrelam a dinâmicas de produção e atualização de hierarquias (entre e no interior de diversos campos sociais) e processos de (des)legitimação, (des)qualificação, in/exclusão de sujeitos, saberes, modo de ver, práticas e agendas políticas e educacionais.

\section{Introdução}

A discussão sobre o corpo na Educação Física, tende a constituir teorias a esse respeito. Isso se justifica pela ideia de que a concepção de corpo presente pode provocar determinadas práticas pedagógicas, uma vez que, ambas (concepções de corpo e metodologias de ensino) tendem a estar apoiadas nos mesmos paradigmas epistemológicos. Dificilmente, um professor que entende o corpo como uma máquina irá tratá-lo como meio de comunicação com o outro ou vice-versa.

A relação destes objetos - corpo e prática pedagógica - tende a ser permeada por discursos filosóficos e científicos, sendo esse último predominante no contexto da modernidade. Todavia: "É importante destacar que os discursos científicos [...] não

\footnotetext{
${ }^{3}$ A concepção e a condução de políticas de educação envolvem espaços, estratos decisionais, agentes, saberes, práticas, concepções e interesses diversificados, animados por tensões produzidas dentro e fora dos campos do Estado e dos sistemas de ensino. Sobre campo social, ver: Bourdieu (1992).

$4 \mathrm{Na}$ escola, a "linguagem, as táticas de organização e de classificação, os distintos procedimentos das disciplinas escolares são, todos, campos de um exercício (desigual) de poder. Currículos, regulamentos, instrumentos de avaliação e ordenamento dividem, hierarquizam, subordinam, legitimam ou desqualificam os sujeitos" (LOURO, 2004a, p.84-85).
} 
ocorreram linearmente, um substituindo o outro de forma sequencial e coerente. Eles aconteceram e ainda acontecem de forma dinâmica e simultaneamente [...]" (DAÓLIO, 1998, p.60). O comentário de Daólio poderia ser direcionado às discussões em outros campos do conhecimento, entre eles, a filosofia e, na Educação Física, os inúmeros debates existentes desde os anos de 1980, não tem necessariamente transformado o quadro de coexistência de teorias diversificadas.

O presente estudo pretende dialogar com diferentes concepções de corpo apresentadas na filosofia e nas ciências humanas e sociais, sobretudo, com alguns autores da sociologia, entre eles, Platão, Santo Agostinho, Descartes, Marx, Hegel. Os mesmos permitem discutir as possibilidades de intervenção da Educação Física em diferentes espaços de atuação, porquanto, o trato com o corpo irá influenciar indubitavelmente, a forma como os educadores entendem o significado de homem e da sociedade, principalmente quando a relação estabelecida acontece no ambiente escolar, embora, o mesmo não seja o único ambiente educativo de intervenção do profissional (NASCIMENTO; FARIAS, 2012). Desta maneira, perceber a concepção de corpo dos acadêmicos do campo de conhecimento da Educação Física permite refletir sobre a atuação nos próximos anos.

Assim sendo, o problema central deste trabalho é saber: existem diferenças entre as concepções de corpo dos acadêmicos de $1^{\circ}$ e $8^{\circ}$ períodos dos cursos de licenciatura em Educação Física? Desse modo, o objetivo geral é identificar e comparar as concepções de corpo de alunos de $1^{\circ}$ e $8^{\circ}$ períodos de licenciatura em Educação Física de duas instituições de ensino de Goiás.

Para atingir o objetivo proposto, o texto será dividido em três seções, sendo, a primeira, usada para debater as concepções de corpo presentes na literatura, tanto de alguns autores considerados clássicos na filosofia e na sociologia, como, também, de pesquisadores da Educação Física que se debruçaram sobre concepções de corpo com diferentes grupos.

No segundo tópico será apresentada a proposta metodológica da pesquisa feita com alunos de duas instituições de ensino superior, sendo uma pública e uma particular. 0 terceiro tópico traz a apresentação, análise e discussão dos dados. 


\section{Concepções de corpo: das concepções filosóficas e sociais à compreensão de} acadêmicos e professores de cursos de licenciatura em educação física

O diálogo a respeito das concepções de corpo vem sendo travado por séculos e está presente na filosofia e na sociologia. Apesar de alguns debates serem considerados remotos, muitas das formas de se refletir a respeito do corpo estão presentes na atualidade, pois, aparentemente, algumas dessas visões, não foram superadas. Desse modo, mesmo de maneira rápida, devido aos limites deste artigo, apresentamos algumas ideias sobre o tema, considerando não as classificações tradicionais, mas, acima de tudo o debate constituído pelo processo de tensão exercido e discutido entre o corpo e a alma; o corpo material (coisa, máquina, ou apenas biológico), o qual não dialoga com outras dimensões que estão fora de si; o corpo em sua relação com o outro corpo e com o mundo; o corpo em sua condição de não existência, ou de hibridismo, um corpo pós-moderno.

A primeira maneira de se refletir sobre o corpo, está na condição de analisá-lo por sua relação com a alma, ou ainda, com outra forma de expressão posta na modernidade: a mente. Esse debate vem sendo tratado, na filosofia, desde a Antiguidade e do Medievo por pensadores como Platão (2008; 2009) e Santo Agostinho (1973a; 1973b), entre outros. Esses autores têm, como ponto em comum, a compreensão de que a alma prevalece sobre o corpo, uma vez que este é finito e passível de paixões e equívocos, enquanto aquela é infinita e vinculada a Deus ou ao mundo das ideias, logo, infinita, ou ainda, imortal. Para estes autores, Deus e/ou o mundo das ideias se configuram como a fonte de toda a verdade, a possibilidade da felicidade plena. Desse modo, essa compreensão de corpo é denominada aqui como o Corpo da Alma.

Outra forma de se compreender o corpo está mais presente nos períodos do lluminismo e da Modernidade, que tendem a tratá-lo como algo em si mesmo. Essa expressão de pensamento não vincula, necessariamente, o corpo à alma, mas aquele é visto em sua materialidade como máquina, coisa, ou componente orgânico. Tal visão é, aqui, denominada de corpo próprio ${ }^{5}$, e está fundamentada por autores como Descartes (2007;

\footnotetext{
${ }^{5}$ Para Merleau-Ponty (1999, p. 78-9), “Os movimentos do corpo próprio são naturalmente investidos de certa significação perceptiva, eles formam, com os fenômenos exteriores, um sistema tão bem ligado que a percepção externa "leva em conta" o deslocamento dos órgãos perceptivos, encontra neles, senão a explicação expressa, pelo menos o motivo das mudanças que intervieram no espetáculo, e assim pode compreendê-las imediatamente". Assim, pretende-se demonstrar que a compreensão desse filósofo é diferente da aqui apresentada, considerando que, neste texto, o corpo não dialoga com a percepção dos fenômenos exteriores, ele é visto nele mesmo.
} 
2005) e La Mettrie, sendo este último um filósofo e médico francês do século XVII, apresentado por Rouanet (2003) e Romero (2000).

Outro modo de considerar a questão do corpo está vinculado à relação estabelecida com o outro e com o mundo. Essa conexão não se estabelece apenas entre seres humanos, mas destes com o mundo/natureza ou no processo de relações sociais. Alguns autores, apesar da divergência paradigmática presente, podem se adequar a tal análise como são os casos de Foucault (1999; 2002); Hegel (2003), Marx (2002), Merleau-Ponty (1999), pois, todos eles discutem as condições das pessoas face às suas relações com o mundo, a natureza e a sociedade. Por isso, essa concepção é, aqui, apresentada como o Corpo com o Mundo.

Por fim, é possível discutir a perspectiva do corpo ser visto como um elemento híbrido, com as próteses de silicone, ou ainda, sem ser visto como um elemento material da vida humana. Para autores como Le Breton (2010), os corpos não existem, o que existem são os seres humanos, homens e mulheres que se movimentam e vivem. Para o citado autor, o corpo é apenas um objeto a ser estudado e, por isso, com a perspectiva de um corpo não material, provavelmente não existente, este corpo é definido, aqui, como o corpo pósmoderno.

Além dos autores mencionados anteriormente, provenientes de ciências mães como a sociologia, ou de outras formas de saber tradicional como a filosofia, existe a possibilidade de articular o debate com uma série de autores nacionais, com produções significativas nas duas últimas décadas do século XX e primeiras décadas do século XXI, com os quais podemos dialogar e estabelecer reflexões expressivas, como são os casos de Soares (2004); Silva (2001); Goldenberg (2006); Daolio (2005); Rouanet (2003), entre outros. Esses pesquisadores se debruçaram sobre a questão do corpo, dialogando, em alguns momentos, não apenas com os referenciais da filosofia e da sociologia, mas, também, da antropologia, da psicologia e da história, por exemplo.

Nessas análises feitas sobre o corpo, sobretudo, quando o debate é feito com e pela Educação Física, as reflexões e dados empíricos demonstram preocupações com os objetivos das ginásticas (SOARES, 2004), das práticas pedagógicas na escola (DAOLIO, 2005), com as construções de capitais culturais (GOLDENBERG, 2006), e com as racionalidades modernas (SILVA, 2001). 
Uma evidência da construção teórica a respeito do corpo na Educação Física, nas duas últimas décadas do século XX, é a pesquisa realizada por Medeiros (1999) a partir de uma análise documental nos livros brasileiros de Educação Física da década de 1980 e 1990. Em seu estudo, Medeiros (1999) demonstra que as concepções de corpo estão presentes em vários desses textos, sendo que, em alguns momentos, os corpos são denunciados, por serem tratados como máquina, forma física ou sistemas biológicos, enquanto, por outro lado, os corpos também são anunciados na perspectiva de serem considerados não apenas como objetos de estudo, mas como sujeitos e como representação de seu tempo e de suas determinações históricas.

Além dessas análises, alguns estudos recentes (SILVA et al, 2009; SILVA, SILVA; LÜDORF, 2011) estão sendo feitos a respeito de concepções de corpo de pesquisadores, professores e alunos de Educação Física. Por exemplo, na pesquisa realizada por Silva et al (2009), em uma Universidade pública do Rio de Janeiro, acadêmicos do primeiro e últimos períodos de um curso de Educação Física responderam a um questionário, com os objetivos de conhecer e comparar a sua visão de corpo, bem como, investigar de que forma relacionam o corpo à Educação Física e à prática profissional.

No referido trabalho foram aplicados questionários, com seis questões abertas, e responderam ao questionário 103 acadêmicos, sendo 56 do primeiro período e 47 dos últimos períodos. Foram analisadas questões específicas que tornaram possível perceber a concepção de corpo daqueles acadêmicos e a relação dessa compreensão com a prática pedagógica de Educação Física. Na análise, as visões adotadas por Silva et al (2009) apresentam três pontos centrais, sendo eles:

10. Corpo à parte: os autores consideraram: "[...] referir ao corpo, considerado como simples suporte da pessoa, um objeto dissociado do homem, uma estrutura passível de ser modificada, cujas peças podem ser substituídas" (SILVA et al, 2009, p. 115). Nesse caso, foram classificadas as respostas que faziam menção ao corpo máquina, simples matéria, veículo.

2․ Corpo interativo: recorrente nas falas a presença do homem dual, ou seja, corpo e alma; "Dessa maneira, o corpo foi caracterizado como união ou integração entre as esferas física e espiritual, ou física e cognitiva" (SILVA et al, 2009, p. 116). 
3‥ Corpo interativo social: corpo como meio de interação social "[...] um meio de comunicação, de expressão e de contato direto com o mundo" (SILVA et al, 2009, p. 116).

O quadro 1 apresenta as respostas dos alunos pesquisados no Rio de Janeiro, de acordo com o período de graduação.

\begin{tabular}{|c|c|}
\hline Graduandos de Primeiro Período & Graduandos de Últimos Períodos \\
\hline \multicolumn{2}{|c|}{ Concepções de corpo } \\
\hline Corpo à parte (31) & Corpo à parte (18) \\
\hline Corpo Interativo (9) & Corpo Interativo Social (13) \\
\hline Corpo Interativo Social (8) & Corpo Interativo (3) \\
\hline
\end{tabular}

Quadro 1 - Análise comparativa entre graduandos de primeiro e últimos períodos de Educação Física. Fonte: adaptado de SILVA et al, 2009, p. 115.

As análises feitas a partir da classificação e tabulação dos dados, pelos pesquisadores, dizem respeito à mudança significativa em relação à concepção de corpo do primeiro período comparado à dos últimos períodos do curso de Educação Física daquela instituição. Apesar de a mudança das concepções ser notada pelo aumento das concepções do corpo interativo social nos últimos períodos, ainda há maior predominância das concepções de corpo à parte. Para os autores, tais aspectos podem ser decorrentes das disciplinas oferecidas pelo curso em que, inicialmente, existe o predomínio de disciplinas das ciências biológicas e, nos últimos períodos do curso, há maior influência das disciplinas de caráter pedagógico (SILVA et al, 2009).

A pesquisa realizada teve como foco, também, identificar como a Educação Física lida com o corpo. Evidencia-se, então, uma percepção não existente no primeiro período, a de corporeidade:

Aqui parece haver outro indicativo de alteração na maneira como os acadêmicos compreendem o corpo, provavelmente decorrente do processo de formação. 0 fato da perspectiva técnico-biológica ter esvaecido, ao mesmo tempo em que surge a da corporeidade, pode estar relacionado ao conhecimento teórico decorrente das disciplinas cursadas (SILVA et al, 2009, p. 119).

Em relação à forma de interferência dos professores de Educação Física na visão de corpo de seus alunos, foi unânime a opinião de que há interferência pelo professor sobre a forma como os alunos concebem o corpo. O que chamou a atenção de Silva et al (2009) es 
foi o não aparecimento da Educação Física, enquanto área da educativa na perspectiva da educação humana. Vejamos:

\begin{abstract}
Se a relevância alcançada pela categoria pedagógica é digna de nota, pode ser considerado até certo ponto surpreendente o fato de não ter sido mencionada a educação na perspectiva de formação humana, tal como apregoam as tendências renovadoras da Educação Física brasileira. Esse dado pode representar que, embora as tendências pedagógicas venham sendo amplamente discutidas no âmbito teórico, ainda a aplicação prática ou a sua disseminação nos cursos de formação de professores é lenta e atinge uma parcela de professores e alunos ainda modestamente (SILVA et al, 2009, p. 121).
\end{abstract}

A citação anterior demonstra uma dissonância entre as discussões atuais, com as concepções dos acadêmicos. Em outra pesquisa realizada (LÜDORF, 2003) detecta-se a diferença da concepção de corpo por parte dos professores universitários do curso de Educação Física em uma Universidade Pública do Rio de Janeiro. Pesquisa na qual dez professores responderam um questionário com perguntas abertas, e as respostas foram organizadas em forma de um continuum, ou seja, as análises foram classificadas como sendo: corpo "fragmentado" postura técnica/ biológica, corpo "sociocultural/político" postura crítica e no meio destes dois extremos estariam as respostas com posição intermediária (LÜDORF, 2003, p.4).

$\mathrm{Na}$ análise dos dados coletados foram feitas algumas observações importantes, como: as concepções de corpo entre os professores variam de acordo com a disciplina que ministram, sendo comuns professores na posição técnico/biológica trabalharem também em clubes ou condomínios, os professores na posição intermediária (mais ligada à concepção de corpo na corporeidade) estariam ligados à disciplina de Arte Corporal e História. Já os professores na postura crítica estariam ligados às áreas de Educação Física escolar e Epistemologia. Na pesquisa os professores se distribuíram de forma equilibrada dentro das três posições (LÜDORF, 2003). Assim, como na pesquisa entre acadêmicos, há grande divergência nas concepções de corpo entre os professores.

Nas considerações finais, Lüdorf (2003) destaca a refutação de sua hipótese, de que os professores de cursos de educação física possuíam, ainda, uma perspectiva de corpo fragmentada, desconsiderando outras possibilidades teóricas. De acordo com o estudo, outras perspectivas somam-se a esta, sendo diferente das concepções biológicas predominantes na Educação Física. Pelo estudo apresentado, é possível notar uma progressão acerca da concepção crítica de corpo e até mesmo intermediária, que tem 
ganhado novos adeptos. Tal mudança influencia, sobremaneira, a forma como os professores de Educação Física, encaram e lidam com os alunos, o que é um avanço rumo à compreensão justa do homem.

Outra pesquisa realizada por Silva, Silva e Lüdorf (2011) envolveu um total de 154 estudantes de duas universidades do Rio de Janeiro: 56 cursavam o 1o período e 47 o 8으 período de uma universidade pública, totalizando 103 alunos; mais 51 estudantes matriculados numa universidade privada, sendo 31 do 1 o Período e 20 do 8 o Período.

Os resultados são descritos no quadro 2.

\begin{tabular}{|c|c|c|c|c|}
\hline Universidades & \multicolumn{2}{|c|}{ Pública } & \multicolumn{2}{c|}{ Privada } \\
\hline Períodos & Primeiro & Últimos & Primeiro & Últimos \\
\hline \multirow{4}{*}{ Categorias } & Corpo à parte (31) & Corpo à parte (18) & Corpo à parte (22) & Corpo à parte (13) \\
\cline { 2 - 5 } & $\begin{array}{c}\text { Corpo Interativo } \\
(9)\end{array}$ & $\begin{array}{c}\text { Corpo Interativo } \\
(13)\end{array}$ & $\begin{array}{c}\text { Corpo Interativo } \\
(1)\end{array}$ & $\begin{array}{c}\text { Corpo Interativo } \\
\text { (4) }\end{array}$ \\
\cline { 2 - 5 } & $\begin{array}{c}\text { Corpo Interativo- } \\
\text { Social (8) }\end{array}$ & $\begin{array}{c}\text { Corpo Interativo- } \\
\text { Social (3) }\end{array}$ & $\begin{array}{c}\text { Corpo Interativo- } \\
\text { Social (1) }\end{array}$ & $\begin{array}{c}\text { Corpo Interativo- } \\
\text { Social (3) }\end{array}$ \\
\hline
\end{tabular}

Quadro 2 - Quadro comparativo sobre as concepções de corpo dos graduandos

Fonte: adaptado de Silva; Silva; Lüdorf, 2011, p.61.

De acordo com os autores:

Nesse caso, analisando de maneira comparativa as universidades e períodos, observa-se que, embora o corpo à parte permaneça o mais citado, a categoria corpo interativo-social que, nos primeiros períodos era pouco mencionada, surge com mais intensidade nos últimos períodos, sobrepondo-se à categoria corpo interativo. Ainda que pareça haver influência da formação acadêmica na emersão da noção de corpo inclinada a uma perspectiva sociocultural, é importante relativizar e compreender o alcance da afirmativa, principalmente diante dos demais resultados [...] (SILVA; SILVA; LÜDORF, 2011, p. 63).

Assim, é possível identificar uma pequena mudança nas concepções de corpo apresentadas nos últimos períodos, apesar de identificar-se, ainda, o predomínio das visões denominadas de corpo à parte, as quais são constituídas "[...] para se referir ao corpo considerado como simples suporte da pessoa, um objeto dissociado do homem, passível de ser modificado, como uma estrutura modular cujas peças podem ser substituídas" (LE BRETON, 2003, p. 16). 
Esse dado, provavelmente, demonstra a dificuldade das pessoas compreenderem o que é o corpo e o seu sentido do ponto de vista individual. É possível, ainda, pensar que a questão não seja fácil de ser resolvida e, talvez, precise-se considerar o fato de não só não haver o conhecimento sobre as percepções do corpo, como também, uma provável dificuldade no trato com a corporalidade.

\section{Aspectos metodológicos}

Como metodologia, optou-se por um plano de investigação descritivo, utilizado quando o "[...] foco essencial destes estudos reside no desejo de conhecer a comunidade, seus traços característicos, suas gente, seus problemas [...], sua educação, [...] etc." (TRIVIÑOS, 1987, p.110). Para tanto, foram aplicados 143 questionários aos acadêmicos de $1^{\circ}$ e $8^{\circ}$ períodos dos cursos de Licenciatura em Educação Física de uma Instituição Pública Estadual (IE) e uma Instituição Privada (IP), nos períodos matutino e vespertino. A pesquisa atende os requisitos da Resolução 196/96 e foi aprovado pelo comitê de Ética da Universidade Católica de Goiás com o número CAAE - 0088.0.168.000-09.

Dos questionários respondidos, 109 acadêmicos cursam o $1^{\circ}$ período do curso de Educação Física (67 da IP e 42 da IE) e 34 cursam o $8^{\circ}$ período (15 da IP e 19 da IE). Sendo que destes, 75 são do sexo masculino e 68 do sexo feminino, com faixa etária variando de 16-43 anos.

Para este texto foi analisada a seguinte questão: Para você o que é o corpo? Essa questão foi selecionada entre outras de um protocolo maior de uma pesquisa que pretendia avaliar não apenas a concepção de corpo dos estudantes, mas, também, discutir com as compreensões de corpo saudável e belo.

O instrumento utilizado para pesquisa foi elaborado especificamente para a mesma e foi submetido a um estudo piloto com alunos de outro curso de Licenciatura em Educação Física da cidade. Os dados foram analisados a partir da análise de conteúdo proposta por Bardin (2010). 


\section{$4 \quad 0$ contexto empírico da pesquisa e o diálogo com a literatura}

Devido à abordagem qualitativa da pesquisa, a mesma apresenta uma parte de suas informações em quadros, os quais expressam, por meio da escrita dos alunos, os aspectos relevantes para a análise realizada.

As concepções de corpo são expressas por meio de algumas das respostas dadas pelas pessoas pesquisadas, ao mesmo tempo em que foram estabelecidas categorias, propostas na primeira parte deste texto (corpo da alma, corpo próprio, corpo com o mundo, corpo pós-moderno). As categorias definidas foram fundamentadas a partir das relações que o corpo faz com ele mesmo, com a alma, com o mundo e com o hibridismo proposto pela pós-modernidade. Destarte, a análise se constitui pelas inferências possíveis dadas pelo sentido e significado identificado na literatura e nas respostas apresentadas.

Na classificação corpo da alma, temos o corpo visto como submisso à alma, o homem é compreendido na sua divisão entre corpo e alma, na qual existe uma predominância da alma sobre o corpo. Esta hierarquia influencia historicamente as concepções de corpo:

[...] a história parece sacramentar a superioridade dos valores espirituais sobre os materiais, constatada em todas as culturas. Assim o corpo e seu cultivo só podem ser considerados enquanto são o palco das demonstrações, das "finesses" do espírito [...], pois a educação do corpo desenvolveria uma mente sadia ou uma alma harmoniosa, desde que houvesse um corpo sadio ou um corpo controlado (SANTIN, 2003, p. 32).

Nesse sentido, alguns dos elementos apresentados pelos alunos pesquisados, parecem confirmar essa forma de compreender o corpo. Tais compreensões estão expressas no quadro 3:

\begin{tabular}{|c|l|}
\hline Aluno & \multicolumn{1}{|c|}{ Construções sobre o corpo da alma apresentada pelos Pesquisados } \\
\hline IE1M19 & Corpo é a matéria que através da mente se relaciona com outros indivíduos. \\
\hline IE1M13 & $\begin{array}{l}\text { Corpo é um instrumento que é utilizado de uma forma coesa com a mente [...], onde a } \\
\text { mente comanda o corpo. }\end{array}$ \\
\hline IE1M14 & $\begin{array}{l}\text { Corpo é instrumento da alma, e que deve ser cuidado, pois é a base de seus } \\
\text { pensamentos [...]. }\end{array}$ \\
\hline
\end{tabular}

Quadro 3 - Expressões e Frases das pessoas entrevistadas relacionadas com a concepção de corpo da alma.

\footnotetext{
${ }^{6}$ A identificação dos sujeitos está sendo feita pela sua instituição de vínculo (IE ou IP), pelo Período (1 ou 8), Pelo sexo (M ou F) e pelo número de sequência. Por isso, este sujeito está identificado como (IE1M14).
} 
Desse modo, as construções elaboradas pelos pesquisados nesta categoria indicam um pensamento ainda muito vinculado à compreensão do ser humano como um ser dual, no qual as questões da mente e/ou do espírito sempre se destacam em relação ao corpo finito e material. Do ponto de vista do contexto atual, e até mesmo dos estudos mencionados, como o de Santin (2003), há necessidade de se entender o ser humano como uma totalidade na qual, a separação entre o corpo e a alma/espírito/mente, aconteça de forma meramente didática, para a compreensão de um dado contexto.

$\mathrm{Na}$ classificação de corpo próprio, tem-se a ideia de corpo entendido nele mesmo, sem relações significativas com outros componentes que sejam externos (o mundo) ou internos e diferenciados (a alma, a mente ou o espírito) em muitos casos, está presente a concepção de corpo máquina ou instrumento. Diria Soares $(2004$, p. 20): “O corpo individual, como unidade produtiva, máquina menor da engrenagem da indústria capitalista [...]". Essas ideias refletem sobre o corpo como simples matéria, ou ainda como simples arsenal biológico. Essa concepção pode ser identificada em alguns dos dados, quando são apresentadas expressões como as demonstradas no quadro 4.

As concepções aqui apresentadas estão, provavelmente, entre as mais tradicionais na Educação Física e, ao mesmo tempo, são demonstradas no cotidiano, sobretudo, na mídia. A concepção de um corpo máquina, em muito se vincula à perspectiva do modo de produção capitalista, o qual tem como foco o desenvolvimento de um corpo pautado pela ideia de capital (GOLDENBERG, 2006). Esse debate, provavelmente, só será superado em uma possível mudança do modo de produção vigente.

\begin{tabular}{|l|l|}
\hline \multicolumn{1}{|c|}{ Aluno } & \multicolumn{1}{|c|}{ Elaborações sobre o Corpo Próprio desenvolvidos pelos Pesquisados } \\
\hline IE8M5 & $\begin{array}{l}\text { Complexo que sustenta, protege e funciona através da interdependência de vários } \\
\text { sistemas. }\end{array}$ \\
\hline IE1F14 & O corpo é uma estrutura que funciona diante de estímulos. \\
\hline IP8F1 & $\begin{array}{l}\text { Estrutura funcional composta de sistemas energéticos, cardíaco, estrutural, entre } \\
\text { outros. Além de ser a nossa ferramenta de sobrevivência e trabalho. }\end{array}$ \\
\hline
\end{tabular}

Quadro 4 - Expressões e Frases das pessoas entrevistadas relacionadas com a concepção de Corpo Próprio. 
Outra categoria proposta é a noção do corpo com o Mundo. Esta compreende o corpo como espaço de intervenção, meio de comunicação, sentidos e significados. Determina e é determinado pela sociedade, porque dialoga com os outros seres humanos e com a natureza. Tal concepção compreende o corpo como determinado pelo modo de produção de um dado momento histórico, o qual é responsável por tornar o homem mercadoria, alienado e, portanto, fetiche. Nesta categoria o corpo é definido como uma construção sociocultural como defendido por Soares (2005) e Daólio (2005). Mas, outra possível análise sobre o corpo, enquanto meio de relação do ser humano com o mundo pode ser descrita, em uma passagem sobre o corpo do camponês de Bourdieu. O autor comenta:

Em tal situação, o camponês é levado a introjetar a imagem que os outros fazem dele, mesmo quando se trata de um mero estereótipo. Passa a perceber seu corpo como corpo cunhado pela impressão social, como corpo empaysanit, rude, carregando o traço das atitudes e atividades associadas à vida camponesa. Em conseqüência, fica embaraçado em relação a seu corpo e em seu corpo. É por apreender seu corpo como corpo de camponês que tem dele uma consciência infeliz. É por apreender seu corpo como corpo rude que toma consciência de ser camponês rústico. Não é exagero presumir que a tomada de consciência de seu corpo é, para o camponês, a ocasião privilegiada da tomada de consciência da condição camponesa (BOURDIEU, 2006, p.87).

A forma como o camponês descrito por Bourdieu (2006) introjeta a sua compreensão de corpo, ocorre devido ao fato de o mesmo estabelecer relações com outros seres humanos, de lugares distintos, com trabalhos diversos e condições corporais discrepantes daquelas apresentadas por eles.

Na pesquisa realizada, algumas descrições ilustram esta categoria:

\begin{tabular}{|l|l|}
\hline Aluno & Descrição da Perspectiva de Corpo com o Mundo apresentada pelos Pesquisados \\
\hline IP8F6 & O corpo é o meio pelo qual relaciono-me com o mundo [...]. \\
\hline IE8F7 & $\begin{array}{l}\text { Corpo é o reflexo da cultura é por meio dele que as sociedades se expressam. [...] e } \\
\text { assim formam os corpos que são substâncias sócio-político e culturais. }\end{array}$ \\
\hline
\end{tabular}

Quadro 5 - Descrições das pessoas entrevistadas relacionadas com a concepção de corpo próprio.

Nas passagens apresentadas no quadro 5, apesar da possível discrepância de autores quando se confronta a literatura (uma visão mais próxima de Merleau-Ponty da aluna IP8F6, e outra próxima do Marxismo de IE8F7), ambas trazem para o centro da relação do corpo o diálogo com as condições objetivas de existência, seja no confronto com o mundo enquanto 
o local de existência e interação com outros seres humanos, seja na compreensão do corpo como substância sociopolítica e cultural, condição possivelmente entendida a partir das condições materiais da existência (MARX; ENGELS, 1998). Destarte, a perspectiva apresentada, traz para o debate do corpo a ampliação das discussões como aquelas apresentadas por Silva et al (2009) e Silva, Silva e Lüdorf (2011).

Não foi possível identificar nas respostas dos acadêmicos pesquisados, nenhuma resposta que se aproximasse da questão do corpo pós-moderno, discutida anteriormente.

Apesar da análise realizada anteriormente, merece destaque neste estudo o fato de os acadêmicos dos $1^{\circ}$ períodos, $21,42 \%$ da IE e 5,97\% da IP se adequarem à categoria do corpo da alma. É possível que conhecimentos de Filosofia advindos do ensino médio ou da disciplina sobre esse assunto, ministrada no início do próprio curso de formação, possam influenciar na concepção dos alunos. Filósofos como Platão (2008) são conhecidos por apresentarem o homem como ser dual, pensamento muito presente na atualidade, e evidenciado nas respostas dos alunos avaliados.

É possível perceber que em relação ao $1^{\circ}$ período, os alunos do $8^{\circ}$ período da $\mathrm{IE}$ $(10,52 \%)$ apresentaram uma queda significativa na concepção de corpo da alma, enquanto na IP, foi possível identificar um pequeno aumento nessa categoria. Essas reflexões também se aproximam daquelas apresentadas por Silva et al (2009) e Silva, Silva e Lüdorf (2011), uma vez que essa concepção se aproxima da perspectiva de corpo interativo, haja vista, haver um diálogo possível com a alma na compreensão exposta por esses autores.

Quanto à ideia de corpo próprio, a mesma se apresenta com certa frequência entre os acadêmicos do $1^{\circ}$ período, e representa a grande maioria das opiniões da IE da IP (64,28\% e 79,10\% respectivamente). Já nos $8^{\circ}$ períodos, a incidência é menor e representa 26,31\% IE e 33,33\% da IP. A grande predominância dessa concepção entre os $1^{\circ}$ períodos pode ser explicada pelas abordagens que são feitas normalmente no início dos cursos de licenciatura em educação física, com disciplinas básicas das ciências biológicas como anatomia, fato coincidente com os estudos de Silva et al (2009) e Silva, Silva e Lüdorf (2011). Nesses estudos, a compreensão de corpo a parte é a mais próxima da ideia de corpo próprio adotada neste estudo. Destaca-se, ainda, que essa forma de compreender o corpo também apresenta predomínio no final do curso. Essa concepção aparece entre 18 alunos dos últimos períodos da IE, enquanto no estudo de Silva et al (2009) e Silva, Silva e Lüdorf (2011) 
os dados da instituição pública são de 31 alunos no primeiro período e 18 dos últimos períodos. Na instituição particular os números são, respectivamente, de 22 estudantes no primeiro período e 13 nos últimos períodos, que demonstram essa compreensão sobre o corpo.

Os dados exibidos remetem à mudança de concepções na categoria Corpo com o Mundo nos $1^{\circ}$ períodos, a qual tem uma representação de $11,90 \%$ na IE e 8,95\% na IP. No 8 o período, encontram-se 63,15\% (IE) e 60\% (IP). Assim, é possível inferir que houve uma tendência de mudança em relação ao conhecimento sobre o corpo ao longo do curso. Apesar de essa categoria englobar várias teorias, o foco central é identificar o corpo não apenas pelo viés biologista ou pela submissão em relação à alma, mas perceber o corpo em um teor mais complexo e crítico. Comparando os dados com Silva et al (2009) e Silva, Silva e Lüdorf (2011) percebe-se, nas pesquisas citadas, um aumento de adeptos que apreendem o corpo criticamente nos últimos períodos, apesar de essa categoria ocupar o segundo lugar dentre as respostas analisadas.

\section{Considerações Finais}

Ao final da análise dos dados é possível identificar uma tendência de modificação nas concepções de corpo quando se confrontam as noções entre $1^{\circ}$ e $8^{\circ}$ períodos. É plausível identificar a tendência de um corpo próprio como predominante no 1o período, provavelmente, decorrente da organização das relações sociais. Enquanto no 8o Período é possível identificar o predomínio do corpo com o mundo. Essa mudança de concepção pode estar relacionada ao currículo, conforme é comentado por Silva, Silva e Lüdorf (2011). Todavia, são necessários outros estudos que façam análises semelhantes e que cruzem os dados com as propostas curriculares de cada instituição.

Outro fator a ser destacado é o corpo visto em sua instrumentalidade, visto como ferramenta de trabalho, como máquina. Essa concepção prevalecente no senso comum, por ser esta a lógica do sistema capitalista, aliena e reifica o ser humano. Esse fator pode justificar o grande percentual de ingressantes que veem o corpo de forma fragmentada. Apesar da indubitável queda, essa concepção ocupa o segundo lugar das mais citadas dentre os alunos dos oitavos períodos das duas Universidades analisadas. 
Nesta pesquisa destaca-se o aumento das concepções de corpo entendido de forma crítica pelos oitavos períodos. Nesse caso, o homem é entendido na sua totalidade, capaz de interferir no seu meio, criar e transformar, e ainda como espaço de intervenção e meio de comunicação.

Enfim, é possível inferir que as concepções se aproximam do senso comum, ou pelo menos daquelas consideradas hegemônicas. Por isso, seria fundamental que os cursos se debruçassem sobre esse debate de forma mais intensa, uma vez que o mesmo pode influenciar não apenas as concepções dos estudantes, como também a sua ação pedagógica posterior.

\section{Referências}

BARDIN, L. Análise de conteúdo. 4.ed. Rev. Ampl. Lisboa: Edições 70, 2010.

BOURDIEU, P. O camponês e seu corpo. Revista de Sociologia e Política, Curitiba, inserir v., n.26, p. 83-92, jun. 2006.

DAÓLIO, J. Da cultura do corpo. 9. ed. Campinas: Papirus, 2005.

DAÓLIO, J. Educação física brasileira: autores e atores da década de 1980. Campinas: Papirus, 1998.

DESCARTES, R. Discurso do método: regras para a direção do espírito. São Paulo: Martin Claret, 2007.

DESCARTES, R. Meditações Metafísicas. São Paulo: Martins Fontes, 2005.

FOUCAULT, M. Vigiar e Punir: nascimento da prisão. 26. ed. Petrópolis: Vozes, 2002.

FOUCAULT, M. Microfísica do poder. 14. ed. Rio de Janeiro: Graal, 1999. 
GOLDENBERG, M. O corpo como capital: para compreender a cultura brasileira. Arquivos em Movimento, Rio de Janeiro, v. 2, n. 2, p. 115-123, jul./dez. 2006.

HEGEL, G.W.F. Fenomenologia do espírito. 2.ed.rev. Petrópolis/Bragança Paulista: Vozes/USF, 2003.

LE BRETON, D. A sociologia do corpo. 4.ed. Petrópolis: Vozes, 2010.

LE BRETON, D. Adeus ao Corpo: antropologia e sociedade. Campinas: Papirus, 2003.

LÜDORF, S. M. A. Concepções de corpo na graduação em educação física: um estudo preliminar com professores. EFDEPORTE: Revista Digital. Buenos Aires, ano 9, n. 66,p. 1-7, 2003. Disponível em: <http://www.efdeportes.com/efd66/corpo.htm>. Acesso em: 13 mai. 2010.

MARX, K. Manuscritos Econômico-Filosóficos. São Paulo: Martin Claret, 2002.

MARX, K.; ENGELS, F. A Ideologia alemã. São Paulo: Martins Fontes, 1998.

MEDEIROS, F. E. Concepções de corpo em livros de educação física: uma leitura em obras de autores brasileiros publicadas nos anos 80 e 90. In: CONGRESSO BRASILEIRO DE CIÊNCIAS DO ESPORTE, 11, 1999, Florianópolis. Anais... Florianópolis: Sedigraf/CBCE, 1999. p. 1310-1317. Caderno 3.

MERLEAU-PONTY, M. Fenomenologia da percepção. 2. ed. São Paulo: Martins Fontes, 1999.

NASCIMENTO, J. V. do; FARIAS, G.O. (Orgs.). Construção da identidade profissional em Educação Física: da formação à intervenção. Florianópolis: Ed. da UDESC, 2012.

PLATÃO. Fédon: diálogos sobre a alma e morte de Sócrates. São Paulo: Martin Claret, 2009.

PLATÃO. A República. São Paulo: Marin Claret, 2008.

ROMERO, E. Do "Tratado da alma" ao "Homem máquina": a possibilidade de explicação do homem apenas pela matéria. Revista Brasileira de Ciências do Esporte, Campinas, v.22, n. 1, p. 11-28, set. 2000. 
ROUANET, S.P. O Homem máquina hoje. In: NOVAES, A. (Org.) O homem-máquina: a ciência manipula o corpo. São Paulo: Companhia das Letras, 2003. p. 37-64.

SANTIN, S. Educação física: uma abordagem filosófica da corporeidade. 2. ed. rev. ljuí: Unijuí, 2003.

SANTO AGOSTINHO. De Magistro. São Paulo: Abril Cultural, 1973a. p.319-56. (Coleção Os pensadores)

SANTO AGOSTINHO. Confissões. São Paulo: Abril Cultural, 1973b. p. 9-316. (Coleção Os Pensadores).

SILVA, A.C. et al. A visão de corpo na perspectiva de graduandos em Educação Física: fragmentada ou integrada? Movimento. Porto Alegre, v. 15, n. 03, p. 109-126, jul./set. 2009. Disponível em: <http://www.seer.ufrgs.br/index. Php/Movimento/article/viewArticle/3036/5831>. Acesso em: 13 mai. 2010.

SILVA, A.C.; SILVA, F.A.G. da; LÜDORF, S. M. A. Formação em educação física: uma análise comparativa de concepções de corpo de graduandos. Movimento. Porto Alegre, v. 17, n. 02, p. 57-74, abr/jun. 2011.

SILVA, A.M. Corpo, Ciência e Mercado: reflexões acerca da gestação de um novo arquétipo da felicidade. Campinas/Florianópolis: Autores Associados/Ed. da UFSC, 2001.

SOARES, C. L. Educação física: raízes europeias e Brasil. 3. ed. Campinas: Autores Associados, 2004.

SOARES, Carmen L. Imagens da Educação no corpo. 3.ed. Campinas Autores Associados, 2005.

TRIVIÑOS, A.N. S. Introdução à pesquisa em Ciências Sociais: a pesquisa qualitativa em educação. São Paulo: Atlas, 1987. 
Enviado em Outubro/2013

Aprovado em Dezembro/2013

Educação: Teoria e Prática/ Rio Claro/Vol. 23, n.44/ p. 05-17/ Set-Dez. 2013. 